\title{
Adventures with a vulnerable knee
}

\author{
Knees are intricate heavy-duty joints that are now, like many other parts of the body, partially replaceable. A knee \\ surgeons' handbook now published shows what lies ahead.
}

THAT people who suffer surgery develop an awesome respect for their surgeons is well known. The psychoanalysts have a word for it: the transference. What follows is an acting out (another analysts' concept) of such a transference, which takes what may be considered the unusual form of a book review. The book, a substantial tome by any standards, with more than 800 pages, is called Knee Surgery (Dunitz, London; $£ 145.00$ ). The editors of a symposium volume are Paul M. Aichroth from the Westminster Hospital, London, and W. Dilworth Cannon Jr, from the University of California, San Francisco. The circumstances of the transference are these.

Just under 20 years ago, the first of the editors removed a cartilage (otherwise a meniscus) from my right knee in an oldfashioned operation, from which it took several months to recover. When, in the summer of 1991, I twisted the same knee and sensed the same old pain, I telephoned asking for advice, arrived for an appointment at what had become the "knee unit" at a private hospital and was offered a disconcerting choice: "Would you like me to do it tomorrow or a week tomorrow?"

It emerged that this informality was a testament to the efficacy of atheroscopy the technique for operating within the knee through three small holes, one of which carries the atheroscope itself, a light source and associated imaging optics which is routinely hitched up to a video recorder. (The equipment and the operation itself were developed in Japan in the early 1960s.) Editor Cannon says that the operation is now the most common of all in North America, and that "few techniques are left for open surgery". In the event, I remember spending a day sleeping off the anaesthetic and watching the abortive coup against Gorbachev before walking out to catch a taxi to the office.

So it was natural to expect as pleasurable an outcome when I banged the same knee against a piece of furniture last October. The $\mathrm{X}$-rays showed a crack near the inner rim of the kneecap, but this time there was no atheroscopy, only pain-killers, physiotherapy, instructions on how to walk (not hop) on crutches, CNN's version of the US election campaign and then the same nonchalant taxi ride to the office. But then I twisted the knee. Nobody knows why the muscles of that leg went into tremor, but I was carted off by ambulance for the second time and told that I had better turn the hospital room into an office. (We never hooked up the modem, though.)

This is how the transference happens. One is told in plain language what is going to happen to one, in this case for at least the week ahead, and one's astonishment at one's willingness to accept the prescription without protest, proof though it may be of one's pathetic eagerness to be cured, is best rationalized by supposing that the instructions come from a supremely confident being. At one stage during that long week, Aichroth casually let slip that "We're doing total knee replacements now".

Indeed they are. Michael A. R. Freeman from the London Hospital gives an account of 21 years of experience with an artificial knee originally developed in collaboration with the Department of Mechanical Engineering at Imperial College, also in London. The trick is to replace the load-bearing surfaces in the knee joint with inert materials without interfering with too many of the attachments within the knee of the tendons and ligaments that hold it together, and which ensure that it will flex without becoming dislocated.

To those who are not surgeons, the procedures are really quite breathtaking. People describe the way of using mechanical jigs that guide the saw-blades that provide flat surfaces onto which to seat the artificial materials. Freeman prefers high-density polyethylene for the lower bearing surface, which is seated (and usually cemented) in the upper part of the trimmed-down tibia, and a cobalt-chromium alloy for the upper surface, wrapped around the head of the femur. But there is plenty of room for argument, and for improvement of design. Some favour titanium rather than the cobalt-chromium alloy. Others are working with knee joints in which the stability is provided by mechanical constraints, as in a hinge. Some even use the word "hinge". .

Nobody offered me a knee replacement, and if they had I hope I would have summoned up the strength to say, "Not yet". In the end, when the knee had failed fully to recover, there was another atheroscopy, debris was excavated from behind the kneecap (bones bleed when broken, one forgets), another miracle cure and another taxi to the office. Ten days in hospital, that took.

I wish now that I had listened more carefully to the advice I was given before I left. Take it easy! Go to physiotherapy regularly, and preferably every day! Do not give up the crutches until your knee feels well! Keep icing that knee! The trouble lies in the layman's sense of what a cure means. Am I well or am I not? If the latter, I will stay in bed, if the former, I will walk. So I bought a walking-stick in a farm supply shop and went on my travels.

To be fair, Aichroth and Cannon is full of the need for retraining the knee after an operation of any kind, under the rubric of rehabilitation. Their associate Dipak V. Patel, from the Wellington Hospital, London, has laced their volume with careful statistical accounts of people's recovery from the several procedures they describe.

Outsiders by now will not be surprised to learn that the evaluation of knee function is in itself a serious issue: indeed, according to a contribution by Aichroth and Patel, there have been so many worthy but uncoordinated attempts at the evaluation of knee function that a committee called the International Knee Documentation Committee has been set up to rationalize them. Like the surgeons they are, they endorse the view that evaluation should not tempt people "to substitute bad accounting for good judgement".

In reality, the fun in this volume is in the sense of daring it repeatedly conveys. There are, for example, enthusiastic accounts of the usefulness of nuclear magnetic resonance in visualizing the soft-tissue structures in the knee. Then there is the business of dealing with the serious injuries of the stabilizing ligaments to which sportspeople are prone. Mathematicians will be intrigued by the insufficiently explicit accounts of where best to re-fix ligaments to the neighbouring bones, but surgeons (for whom the book is written) will be more taken with tales of how to replace them altogether. Plainly the knee is well on the way to being replaceable.

So why my regret at having taken so quickly to a walking-stick? After an overseas journey, I remembered that I was due for a check-up. Slightly querulously, I complained that the knee still hurt, and was told to have patience. That evening, I slipped on the kitchen floor and broke my right femur just above the knee. From where I had fallen, I told the surgeon what had happened. He said he'd look in at the hospital in a couple of hours (by which time it was 2.30 a.m.). No doubt sympathetically, he mentioned that the death rate from broken femurs during the First World War was 90 per cent. The following day he installed a stainless steel plate, complete with an array of screws. Drooling over an X-ray of my thigh, a physiotherapist said "who would have thought anybody could have put that together again?" The knee-cap, as it happens, also seems to be mending. John Maddox 